Лисенко О. В.

кандидат економічних наук, Університет митної справи та фінансів

Lysenko Olena

Candidate of Economic Sciences, University of Customs and Finance

\title{
ПОРІВНЯННЯ МЕТОДІВ КОРОТКОСТРОКОВОГО ПРОГНОЗУВАННЯ ДЛЯ СПАДНОГО ВИРОБНИЧОГО ПРОЦЕСУ
}

Анотація. Роботу присвячено дослідженню та порівнянню методів короткострокового планування та прогнозування. За основу розрахунків прийнято дані підприємства, яке характеризується спадним процесом виробництва, тобто функція доходу підприємства має спадний характер у часовому вимірі. Функція витрат, яка $є$ базовою для проведеного дослідження, також спадає, але меншими темпами порівняно з функцією доходу. Оптимізація управління підприємствами у цілому та планування окремих операційних періодів, як правило, спираються на використання економіко-математичного моделювання та прогнозування змін показників виробничих процесів. Прогноз завжди є багатоваріантним і пропонує кілька альтернативних рішень, тому на основі наведених даних побудовано мультиплікативну економетричну модель динаміки часового ряду та пропорційну прогнозну модель на один період уперед. Обчислено та порівняно похибки прогнозів моделей. Вагомою умовою цього дослідження стала наявність невеликої кількості даних спостережень часового ряду (менше 12), що у кожному разі відображається на точності розрахунків.

Ключові слова: економетрична модель, мультиплікативна модель, авторегресійне рівняння, автокореляційна функція, просторово-часові ряди.

Вступ та постановка проблеми. Моделювання кожного виробничого процесу завжди базується на якомога точнішому, якісному, достовірному прогнозі витрат підприємства на майбутній операційний період. Прогноз виступає основоюприйняття планових рішень. План іпрогноз-це дві стадії планування, які взаємно доповнюють одна одну [1]. Прогноз у своїх об'єктах та завданнях визначається потребами складання планів і зумовлює їх. Кожен план є одноваріантним. Прогноз завжди багатоваріантний і пропонує кілька альтернативних рішень [2]. 3 усієї множини підходів до прогнозування найбільше розповсюдження отримали методи експертних оцінок, методи обробки просторових, часових, просторово-часових сукупностей, методи ситуаційного аналізу [3; 4, с. 164]. Як правило, для обгрунтування та визначення рівня різних планових показників застосовують метод «від досягнутого рівня», тобто балансовий метод, який побудовано на пропорційному методі прогнозування. Прогнозування основних операційних показників (наприклад, витрат) вимагає знаходження та ідентифікації методів і моделей, які за відомими вибірками даних надають найкращий за обраним критерієм результат. У цій роботі використано прогнозний пропорційний метод, в основі якого лежить коригування поточного статистичного показника на темпи змінення базового показника, що зумовлено використанням у дослідженні даних балансової звітності підприємств, і метод побудови економетричних моделей динаміки часових рядів, що зумовлено наявністю трендової, циклічної, сезонної та випадкової компонент у функціях показників витрат. Економетричні моделі динаміки часових рядів, своєю чергою, спираються на методи автокореляційного й регресійного аналізу. Зауважимо, що поняття точності прогнозу трактується через статистичні характеристики. Практичним критерієм, зокрема, мають слугувати похибки прогнозу за вибраними моделями, які, серед іншого, враховують вибіркову дисперсію відхилень реальних значень показників від прогнозованих.

Аналіз останніх досліджень і публікацій. Дослідженню означеного завдання присвячено роботи вітчизняних (Л.В. Антонова, І.О. Бланк, Н.С. Бойцун, О.С. Вент- цель, В.В. Ковальов, Л.І. Лопатников, О.О. Ляховець, О.М. Марюта та ін.) та іноземних (Г. Мінцберг, Дж. Куїн, С. Гошал, Джеймс К. Ван Хорн, Джон М. Вахович-мол., Е. Хелферт) учених. Найбільша увага у цих роботах приділяється короткостроковому плануванню і прогнозуванню та поєднанню системи планування в єдине ціле 3 організаційною структурою підприємства [2, с. 224].

Метою даної роботи $\epsilon$ порівняння існуючих методів короткострокового прогнозування, а саме пропорційного методу та методу побудови економетричної моделі часових рядів показників, для спадного виробничого процесу.

Результати дослідження.

Функції витрат підприємств мають зростаючий характер, спадний характер чи змальовують періодичний виробничий процес, який місить сезонні та циклічні коливання [5, с. 72]. Спадний процес виробництва привертає увагу своєю наближеністю до певного кризового стану підприємства, де він спостерігається. Для стабілізації економічного стану підприємства важливою є точність прогнозу основних виробничих показників на майбутній операційний період.

Розглянемо метод побудови економетричних моделей динаміки часових рядів показників. Дискретний часовий ряд статистичних показників роботи підприємства розглядається як послідовність значень $y_{1}, y_{2}, \ldots, y_{n}$ в момент часу $t$, тобто $y_{t}(t=1,2, \ldots, n)[6$, c. 159]. Часовий ряд також можна представити в такому вигляді: $y_{t}=x_{t}+\varepsilon_{t}$,

де: $x_{t}$ - детермінована випадкова компонента процесу; $\varepsilon_{t}-$ стохастична випадкова компонента процесу.

За наявності в часовому ряді тенденції та циклічних коливань має місце автокореляційна залежність рівнів ряду [7, с. 106]. Коефіцієнти кореляції оцінюються за формулою [8]:

$$
r_{x y}=\frac{\sum\left(x-x^{c p}\right) \cdot\left(y-y^{c p}\right)}{\sqrt{\Sigma\left(x-x^{c p}\right)^{2} \cdot \Sigma\left(y-y^{c p}\right)^{2}}}
$$

Розрахунком коефіцієнтів автокореляції різних рівнів ряду будується автокореляційна функція, яка допомагає 
виявити в часовому ряді наявність чи відсутність трендової компоненти. Коли найбільш високим є автокореляційний коефіцієнт першого порядку, то ряд містить тільки тенденцію. Якщо найбільш високим $є$ коефіцієнт автокореляції порядку $i$, то ряд містить циклічні коливання з періодичністю в $i$ моментів часу. Утому разі коли жоден із коефіцієнтів автокореляції не є значущим, то ряд може не містить тенденції або ряд містить сильну нелінійну тенденцію. Чим сильніше виражена нелінійна тенденція у часовому ряді, тим більше різняться розраховані коефіцієнти.

Далі відбувається аналітичне вирівнювання часового ряду, тобто побудова аналітичної функції, що характеризує залежність рівнів ряду від часу або тренду. Для іiї формалізації найчастіше використовуються такі функції [7, с. 110]: лінійний тренд: $y_{t}=a+b \cdot t$; гіпербола: $y_{t}=a+\frac{b}{t} ;$ експоненційний тренд: $y_{t}=e^{a+b \cdot t} ;$ тренд у формі степеневої функції: $y_{t}=a \cdot t^{b}$; парабола другого та більш високого порядку: $y_{t}=a+b_{1} \cdot t+b_{2} \cdot t^{2}+\ldots+b_{k} \cdot t^{k}$. Параметри кожного $з$ трендів визначаються методом найменших квадратів, де залежна змінна $-y$, а незалежна $t=i=1,2, \ldots, n$.. Найчастіше вибирається рівняння тренду 3 максимальним коефіцієнтом детермінації $R^{2}$.

За зростання чи спадання амплітуди сезонних коливань будується мультиплікативна модель динаміки часових рядів. Мультиплікативна економетрична модель представляється як добуток трендової $T$, сезонної $S$ та випадкової $E$ компонент:

$$
Y=T \cdot S \cdot E
$$

Після розрахунку значень центрованих ковзких середніх $Y_{i u}$ на їх основі будуються рівняння тренду $T$ та за допомогою коефіцієнта детермінації вибирається тип тренду і відповідне йому рівняння, на основі якого обчислюються значення $T$ [7, с. 104].

Оцінка значень циклічного складника $C$ :

$$
C_{i}=\frac{Y_{i u}}{T_{i}} .
$$

Оцінка впливу сезонного та випадкового складників:

$$
S_{t} \cdot E_{t}=\frac{Y_{i}}{Y i u} .
$$

Тоді сезонний складник $S$ розраховується так:

У кожному макроперіоді (циклі) знаходиться сума значень $S_{i} \cdot E_{i}$ без урахування максимального та мінімального значень:

$$
\sum_{i=1}^{n} S_{i} \cdot E_{i}=\sum_{j=1}^{m} S_{i j} \cdot E_{i j}-\max S_{i j} \cdot E_{i j}-\min S_{i j} \cdot E_{i j},
$$

де $i \epsilon[1 ; n]$ - кількість макроперіодів (циклів), $j \epsilon[1 ; m]-$ кількість періодів (кроків) у циклі.

Далі обчислюється оцінка модифікованого середнього значення сезонної компоненти:

$$
S_{i}^{c p}=\frac{\sum_{i=1}^{n} S_{i} \cdot E_{i}}{n} .
$$

У мультиплікативній моделі сума значень сезонного складника за всіма макроперіодами (циклами) повинна дорівнювати кількості періодів у циклі, тому що сезонні впливи за цикл взаємно погашаються.

Коригуючий коефіцієнт:

$$
k=\frac{n}{\sum_{i=1}^{n} S_{i}^{c p}}
$$

Скориговані модифіковані середні сезонного складника:

$$
S_{i}=k \cdot S_{i}^{c p} .
$$

Оцінка значень випадкового складника:

$$
E_{i}=\frac{S_{i} \cdot E_{i}}{S_{i}} .
$$

Абсолютні похибки:

$$
E_{i}^{\prime}=Y_{i}-T_{i} \cdot C_{i} \cdot S_{i}=Y_{i}-Y_{i \varphi} .
$$

Оцінка якості й адитивної і мультиплікативної моделі:

де $Y_{i}^{c p}=\frac{\sum_{i=1}^{n} Y_{i}}{n}-1-\frac{\sum_{i=1}^{n}\left(E_{i}^{\prime}\right)^{2}}{\sum_{i=1}^{n}\left(Y_{i}-Y_{i}^{c p}\right)^{2}}$,

Прогнозне значення $Y_{i}$ у мультиплікативній моделі дорівнює: $Y=T \cdot S \cdot E$.

Звернемося також до пропорційного прогнозного методу [9, с. 260]. На основі темпу зростання обраного показника $D$ перераховуються інші показники балансу. Таким чином, розраховане прогнозне значення витрат на період $i+1$ :

$$
Z_{i+1}^{\prime}=\frac{D_{i}}{D_{i-1}} \cdot Z_{i}
$$

Дослідимо функцію витрат $Z_{i}=Y_{i}$, яка характеризує спадне виробництво [5, с. 83] (табл. 1) та проаналізуємо ii прогнозні значення, отримані на основі розрахунків за допомогою економетричних моделей динаміки часових рядів та на основі пропорційного методу прогнозування. Порівняємо отримані результати та звернемо увагу на похибки прогнозу.

Функція $Z_{i} є$ спадною, має місце скорочення виробництва. На графіку функції (рис. 1) не спостерігається постійна амплітуда коливань значень функції від матсподівання. Це свідчить про те, що сезонна компонента не $\epsilon$ однаковою для різних періодів спостереження. Тобто доречно будувати мультиплікативну економетричну модель. Також розрахуємо прогнозні значення витрат на наступний операційний період за пропорційним методом та порівняємо результати обох прогнозів.

За графіком автокореляційної функції можна зробити висновок, що часовий ряд містить коливання періодичністю 4 інтервали $\left(r_{2}-r_{6}\right)$ (рис. 2,3$)$. Тісна кореляція коефіцієнтів $r_{1}, r_{2}, r_{3}(1,000 ; 0,992 ; 0,997)$ свідчить про наявність лінійного тренда, але розглянемо декілька варіантів рівнянь тренда, які побудуємо після вирівнювання часового ряду методом ковзкої середньої (інтервал розрахунку - 4) та обчислимо центровану ковзку середню. Значення центрованої ковзкої середньої є фактичними даними для побудови рівнянь можливих трендів та відповідних коефіцієнтів детермінації (табл. 2). Наявність лінійного тренда доводять високі коефіцієнти автокореляції першого та другого рівнів, і коефіцієнт детермінації поліноміального тренда є максимальним $\left(R^{2}=0,995\right)$. Але економічні процеси вкрай рідко розвиваються в часі як параболічні функції другого та більш високого рівнів. Окрім того, такі тенденції потребують великої кількості значущих цифр після коми під час розрахунків. Тому вибираємо експоненційний тренд $\left(R^{2}=0,974\right)$.

Після застосування у формулі експоненційного тренда відповідних значень $t$ отримані результати занесено у стовпчик $T_{i}$ (табл. 1). У цьому разі часовий ряд містить замало даних, що заважає визначенню оцінок сезонної 
Таблиця 1

Оцінювання параметрів економетричної прогнозної моделі за функцісю витрат (спадне виробництво)

\begin{tabular}{|c|c|c|c|c|c|c|c|c|c|c|c|c|}
\hline$(t)$ & $t=i$ & $Y_{i}=Z_{i}(100000$ y. o. $)$ & $r_{i}$ & $\overline{\bar{y}_{i}}$ & $\bar{y}_{i}^{\prime}$ & $T_{i}$ & $\hat{C}_{t}$ & $\hat{S}_{i} \hat{E}_{i}$ & $\hat{S}_{i}$ & $\hat{E}_{i}$ & $\hat{E}_{i}^{\prime}$ & $E_{i}{ }^{2}$ \\
\hline 4 & 1 & 14,200 & 1,000 & 14,200 & & & & & & & & \\
\hline 1 & 2 & 14,000 & 0,992 & 13,967 & 14,083 & 13,665 & 1,031 & 0,994 & 1,000 & 0,994 & $-0,083$ & 0,007 \\
\hline 2 & 3 & 13,700 & 0,970 & 13,500 & 13,733 & 12,792 & 1,074 & 0,998 & 1,000 & 0,998 & $-0,033$ & 0,001 \\
\hline 3 & 4 & 12,800 & 0,953 & 12,767 & 13,133 & 11,975 & 1,097 & 0,975 & 1,000 & 0,975 & $-0,333$ & 0,111 \\
\hline 4 & 5 & 11,800 & 0,944 & 11,817 & 12,292 & 11,210 & 1,096 & 0,960 & 1,000 & 0,960 & $-0,492$ & 0,242 \\
\hline 1 & 6 & 10,850 & 0,995 & 10,850 & 11,333 & 10,494 & 1,080 & 0,957 & 1,000 & 0,957 & $-0,483$ & 0,234 \\
\hline 2 & 7 & 9,900 & 1,000 & 9,883 & 10,367 & 9,824 & 1,055 & 0,955 & 1,000 & 0,955 & $-0,467$ & 0,218 \\
\hline 3 & 8 & 8,900 & & 9,400 & 9,642 & 9,196 & 1,048 & 0,923 & 1,000 & 0,923 & $-0,742$ & 0,550 \\
\hline 4 & 9 & 8,873 & \multicolumn{3}{|c|}{ Прогнозне значення } & 8.609 & 1.031 & & 1,000 & & & \\
\hline
\end{tabular}

Тут: $(t)$ - цикл; $t$ - інтервал; $Y_{i}$ - значення функції витрат; $r_{i}-$ значення автокореляційної функції; $\bar{y}_{i}-$ ковзка середня; $\bar{y}_{i}^{\prime}-$ центрована ковзка середня; $T_{i}=y=15,593 e-0,066 x-$ рівняння тренда; $\hat{C}_{t}=\bar{y}_{i}^{\prime} / T_{i}$ - оцінка значень циклічної складової; $\hat{S} \hat{E}_{i}=Y / \bar{y}_{i}^{\prime}-$ оцінка значень сезонного та випадкового складників; $\hat{S}_{i}$ - оцінка значень сезонного складника; $\hat{E}_{i}=\left(\hat{S}_{i} \hat{E}_{i}\right) / \hat{S}_{i}-$ оцінка значень випадкового складника; $\hat{E}_{i}{ }^{\prime}=Y_{i}-T_{i} \hat{C}_{t} \hat{S}_{i}=\left(Y_{i}-\bar{y}^{\prime} \hat{S}_{i}\right)-$ абсолютна похибка; $\hat{E}_{i}{ }^{2}$ - квадрат абсолютної похибки; $Z_{8}$ - отримане прогнозне значення функції витрат.

Джсерело: розраховано автором на основі [5, c. 83]

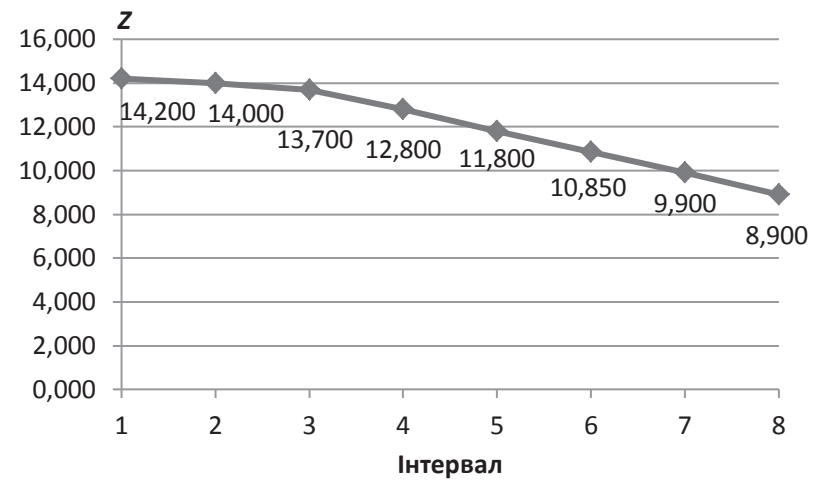

Рис. 1. Графік функції $Z_{i}$ Спадне виробництво

Джерело: побудовано автором на основі [5, с. 83]

$r_{i}$

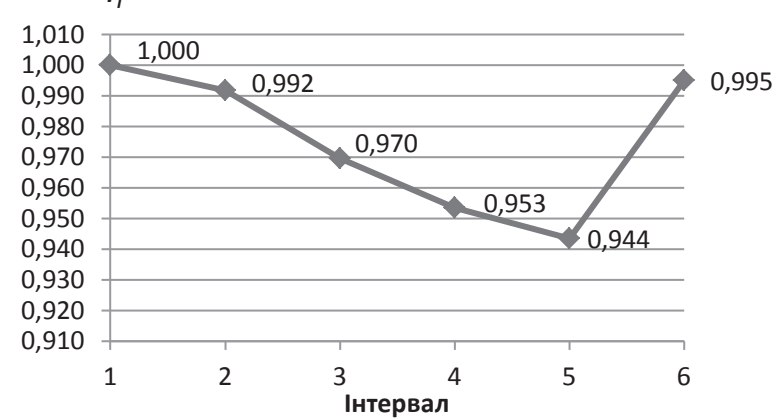

Рис. 2. Графік автокореляційної функції $r_{i}$. Спадне виробництво

Джерело: побудовано автором на основі [5, с. 83]

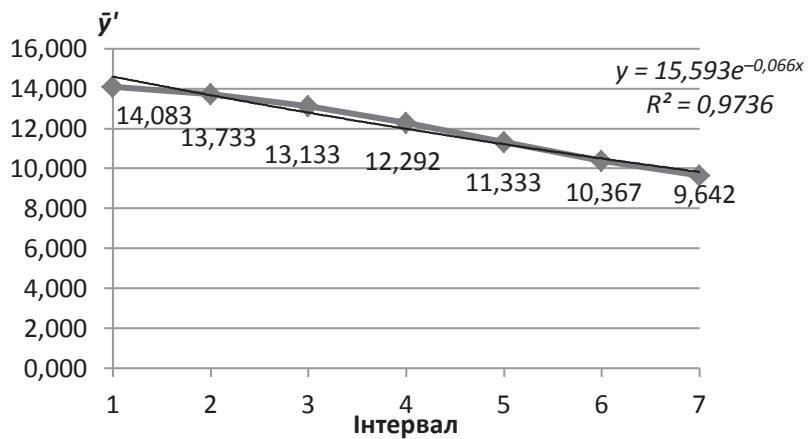

Рис. 3. Графік центрованої ковзкої середньої функції витрат.

Побудова лінії тренда та авторегресійного рівняння. Спадне виробництво

Джерело: побудовано автором на основі [5, с. 83] 
Рівняння трендів, коефіціснти детермінації (спадне виробництво)

\begin{tabular}{|l|ll|}
\hline \multicolumn{1}{|c|}{ Тип тренда } & \multicolumn{1}{|c|}{ Рівняння тренда, коефіціснт детермінації } \\
\hline Лінійний & $y=-0,7807 x+15,206$ & $R^{2}=0,9841$ \\
\hline Логарифмічний & $y=-2,292 \ln (x)+14,874$ & $R^{2}=0,8522$ \\
\hline Поліноміальний & $y=-0,0469 x^{2}-0,4053 x+14,643$ & $R^{2}=0,9948$ \\
\hline Експоненційний & $y=15,593 e^{-0,066 x}$ & $R^{2}=0,9736$ \\
\hline Степеневий & $y=15,119 x^{-0,191}$ & $R^{2}=0,8228$ \\
\hline
\end{tabular}

Джерело: розраховано автором на основі [5, с. 83]

компоненти, хоча іiі наявність не можна заперечувати. Тому запропоновано вважати всі скориговані модифіковані середні $S_{i}=1$, що означає відсутність сезонного складника в економетричній моделі для кількості точок спостереження - 8. Оцінка значень випадкового складника проводиться за значеннями стовпчика: $E_{i}$. Абсолютна похибка для кожного рівня ряду: $E_{i}^{\prime}=Y_{i}-T_{i} \cdot C_{i} \cdot S_{i}$.

Суми квадратів абсолютних похибок та квадратів відхилень рівнів ряду від прогнозних рівнів для спадної функції витрат за розрахунками становлять:

$$
\left(E_{i}^{\prime}\right)^{2}=1,362, \quad \sum\left(Y_{i}-\bar{Y}_{i}\right)^{2}=24,281 .
$$

Похибка прогнозу за мультиплікативною економетричною моделлю за наведеною формулою $є$ невеликою та дорівнює 5,611\%:

$$
R_{i}=\frac{\sum_{i=1}^{n}\left(E_{i}^{\prime}\right)^{2}}{\sum_{i=1}^{n}\left(Y_{i}-Y_{i}^{c p}\right)^{2}} \cdot 100 \%=\frac{1,362}{24,281} \cdot 100 \%=5,611 \%
$$

Мультиплікативна економетрична модель часового ряду, що відображає спадне виробництво, пояснює 94,389\% загальної варіації рівнів часового ряду функції витрат. Це $є$ високим відсотковим прогнозним значенням. Оцінка якості моделі:

$$
R_{\Re}^{2}=1-\frac{\sum_{i=1}^{n}\left(E_{i}^{\prime}\right)^{2}}{\sum_{i=1}^{n}\left(Y_{i}-Y_{i}^{c p}\right)^{2}}=\left(1-\frac{1,362}{24,281}\right)=0,943
$$

Прогнозне значення витрат наступного операційного періоду 9 становитиме:

$Z_{9}=T_{9} \cdot C_{2} \cdot S_{4}=8,609 \cdot 1,031 \cdot 1,000=8,873 \cdot 100000$ y.o.

Задля порівняння 3 результатами прогнозування на основі пропорційного методу для кожного прогнозу розрахуємо середню відносну похибку оцінки прогнозу [6, с. 182].

$$
m_{a}=\left|\frac{1}{n} \sum_{i=1}^{n} \frac{Y_{i}-Y_{i}^{\prime}}{Y_{i}^{\prime}} \cdot 100 \%\right|
$$

де $Y_{i}$ - Фактичне значення витрат за період: $Y_{8}=8,900 \cdot 100000$ y.o.;

$Y_{i}^{\prime}-$ Прогнозне значення витрат за період: $Y_{8}^{\prime}=9,642 \cdot 100000$ y.o.

Оскільки прогноз розраховано на один період уперед, відносну похибку розрахунків можна оцінювати тільки за результатами порівняння фактичного та прогнозного значень наданого останнього рівня ряду 7:

$$
m_{a}=\left|\frac{Y_{8}-Y_{8}^{\prime}}{Y_{8}^{\prime}} \cdot 100 \%\right|=\left|\frac{8,900-9,642}{9,642} \cdot 100 \%\right|=7,692 \%
$$

За пропорційним методом прогнозування маємо такі обчислені показники спадного процесу (табл. 3).

Відношення $\frac{D_{i}}{D_{i-1}}-$ темп змінення показників на кожний наступний період. Тоді прогнозне значення витрат:

$$
\begin{gathered}
Z_{9}^{\prime}=\frac{D_{8}}{D_{7}} \cdot Z_{8}=\frac{9,00}{10,000} \cdot 8,900= \\
=0,900 \cdot 8,900=8,010 \cdot 100000 \text { y.o. }
\end{gathered}
$$

Для обчислення похибок розрахунків звернемося до формул, які використані в мультиплікативній моделі. Похибка прогнозу за пропорційною моделлю дорівнює $1,893 \%$ і є незначною:

$$
R_{i}=\frac{\sum_{i=1}^{n}\left(E_{i}^{\prime}\right)^{2}}{\sum_{i=1}^{n}\left(Y_{i}-Y_{i}^{c p}\right)^{2}} \cdot 100 \%=\frac{0,456}{24,094} \cdot 100 \%=1,893 \%
$$

Прогнозна модель, що відображає виробництво, що ско-

\begin{tabular}{|c|c|c|c|c|c|c|c|}
\hline$t_{i}$ & $\begin{array}{c}Y_{i}=Z_{i}(100000 \\
\text { y. o. })\end{array}$ & $D_{i}$ & $D_{i} / D_{i-1}$ & $Z_{i}^{\prime}$ & $E_{i}(Z)=Y_{i}-Z_{i}^{\prime}$ & $E_{i}^{2}(Z)$ & $\left(Z_{i}-Z_{i}^{\prime}\right) / Z_{i}^{\prime}$ \\
\hline 1 & 14,200 & 14,500 & & & & & \\
\hline 2 & 14,000 & 14,200 & 0,979 & 14,200 & $-0,200$ & 0,040 & $-0,014$ \\
\hline 3 & 13,700 & 13,900 & 0,979 & 13,710 & $-0,010$ & 0,000 & $-0,001$ \\
\hline 4 & 12,800 & 13,000 & 0,935 & 13,411 & $-0,611$ & 0,373 & $-0,046$ \\
\hline 5 & 11,800 & 12,000 & 0,923 & 11,971 & $-0,171$ & 0,029 & $-0,014$ \\
\hline 6 & 10,850 & 11,000 & 0,917 & 10,892 & $-0,042$ & 0,002 & $-0,004$ \\
\hline 7 & 9,900 & 10,000 & 0,909 & 9,946 & $-0,046$ & 0,002 & $-0,005$ \\
\hline 8 & 8,900 & 9,000 & 0,900 & 9,000 & $-0,100$ & 0,010 & $-0,011$ \\
\hline 9 & \multicolumn{3}{|c|}{ Прогнозне значення } & 8,010 & \multicolumn{2}{|c|}{$\left|\Sigma\left(Z_{i}-Z_{i}^{\prime}\right) / Z_{i}^{\prime}\right|$} & 0,094 \\
\hline
\end{tabular}
рочується, яка побудована за пропорційним методом, пояснює 98,107\% загальної зміни значень функції витрат у часі, що $є$ вищим прогнозним значенням порівняно з мультиплікативною економетричною моделлю. Оцінка якості моделі:

$$
R_{\Omega}^{2}=1-\frac{\sum_{i=1}^{n}\left(E_{i}^{\prime}\right)^{2}}{\sum_{i=1}^{n}\left(Y_{i}-Y_{i}^{c p}\right)^{2}}=\left(1-\frac{0,456}{24,094}\right)=0,981
$$

Таблиця 3

Оцінювання прогнозних значень функції витрат за пропорційним методом (спадне виробництво)

Тут: $t_{i}$ - номер інтервалу; $Y_{i}=Z_{i}$ - значення функції витрат; $D_{i}$ - значення функції доходу від реалізації продукції: $D_{i} / D_{-{ }_{-}}-$темп зростання показників; $Z_{i}^{\prime}-$ прогнозні значення функції витрат; $E_{i}(Z)=Y_{i}-Z_{i}^{\prime}-$ абсолютна похибка; $E_{i}^{2}(Z)$ - квадрат абсолютної похибки; $\left|\left(Z_{i}-Z_{i}^{\prime}\right) / Z_{i}^{\prime}\right|-$ модуль відносної похибки; $Z_{8}$ - отримане прогнозне значення функції витрат.

Дэсерело: розраховано автором на основі [5, c. 83] 
Середня відносна похибка оцінки прогнозу [6, с. 182] для спадного процесу буде від’ємною, тому розрахуємо їi модуль:

$m_{a}=\left|\frac{1}{n} \sum_{i=1}^{n} \frac{Y_{i}-Y_{i}{ }^{\prime}}{Y_{i}{ }^{\prime}} \cdot 100 \%\right|=\left|\frac{1}{7} \cdot(-0,094) \cdot 100 \%\right|=1,347 \%$

Зведемо отримані дані так (табл. 4).

Висновки. У розглянутому варіанті спадного виробничого процесу показник похибки прогнозу для пропорційного методу прогнозування менший, аніж в економетричній моделі, середня відносна похибка прогнозування також у рази менша. Оцінка якості моделі, розрахована за пропорційним методом, є більш високою. Прогнозні значення витрат за обома моделями логічно вкладаються у вже існуючий часовий ряд, хоча пропорційна модель надає вищий темп змінення показника. Мультиплікативна економетрична модель потребує певного ряду точок, значень витрат за періоди, кількість яких повинна бути достатньо великою, тому пропорційному методу належить певна перевага, тому що для побудови прогнозних значень на майбутній операційний період потрібні дві дискретних величини, значення витрат за два минулі періоди. За наведеними розрахунками й порівняннями можна зробити висновок про доцільність використання обох методів для прогнозування обсягу витрат на один операційний період уперед.

Таблиця 4

Характеристики економетричної та пропорційної прогнозних моделей (спадне виробництво)

\begin{tabular}{|l|c|c|c|c|c|c|}
\hline \multicolumn{1}{|c|}{ Показник } & $\begin{array}{c}\boldsymbol{Z}_{i-1} \\
(\mathbf{1 0 0 0 0 0} \text { у.о.) }\end{array}$ & $\begin{array}{c}\boldsymbol{Z}_{\boldsymbol{i}} \\
(\mathbf{1 0 0 0 0 0} \text { у.о.) }\end{array}$ & $\begin{array}{c}\boldsymbol{Z}_{\boldsymbol{i + 1}}^{\prime} \\
(\mathbf{1 0 0 0 0 0} \text { у.о.) }\end{array}$ & $\begin{array}{c}\text { Похибка } \\
\text { прогнозу } \boldsymbol{R}\end{array}$ & $\begin{array}{c}\text { Оцінка якості } \\
\text { моделі } \boldsymbol{R}^{\mathbf{2}}\end{array}$ & $\begin{array}{c}\text { Середня відносна } \\
\text { похибка } \boldsymbol{m}_{a}\end{array}$ \\
\hline Мультиплікативна модель & 9,900 & 8,900 & 8,873 & $5,611 \%$ & $0,943(94,389 \%)$ & $7,692 \%$ \\
\hline Пропорційна модель & 9,900 & 8,900 & 8,010 & $1,893 \%$ & $0,981(98,107 \%)$ & $1,347 \%$ \\
\hline
\end{tabular}

$Z_{i+1}-$ прогнозні значення витрат періоду $i+1$.

Джерело: розраховано автором на основі [5, с. 83]

Список використаних джерел:

1. Бланк И.А. Словарь-справочник финансового менеджера. Киев : Ника-Центр, 1998. 480 с.

2. Минцберг Г., Куин Дж., Гошал С. Стратегический процесс / пер. с англ. ; под ред. Ю.Н. Каптуровского. Санкт-Петербург : Питер, 2001. 688 с.

3. Марюта А.Н., Бойцун Н.Е. Экономико-математическое моделирование и оптимизация управления организациями : монография. Днепропетровск : Днепропетр. ун-т, 2006. 540 с.

4. Ковалёв В.В. Финансовый менеджмент. Теория и практика ; 2-е изд., перераб. и доп. Москва : Проспект, 2007.1024 с.

5. Хелферт Э. Техника финансового анализа ; 10-е изд. Санкт-Петербург : Питер, 2003. 640 с.

6. Бережная Е.В., Бережной В.И. Математические методы моделирования экономических систем ; 2-е изд., перераб. и доп. Москва : Финансы и статистика, 2006. 432 с.

7. Антонова Л.В., Ляховець О.О. Економетрика. Миколаїв : ЧДУ ім. П. Могили, 2011. 232 с.

8. Вентцель Е.С. Теория вероятностей : учебник для вузов ; изд. 6-е. Москва : Высшая школа, 1999. 576 с.

9. Лопатников Л.И. Экономико-математический словарь: Словарь современной экономической науки ; 5-е изд., перераб. и доп. Москва : Дело, 2003. 520 с.

\section{References:}

1. Blank I.A. (1998). Slovar-spravochnik finansovogo menedzhera [Financial Manager's Guide and Glossary]. Kiyev: Nika-Tsentr (in Russian), 480 p.

2. Mintsberg G., Quin G., Goshal S. (2001). Strategicheskiy protsess [Strategic Process]. Saint-Petersburg: Piter (in Russian), 688 p.

3. Mariuta A.M., Boitsun N.Ye. (2006). Ekonomiko-matematicheskoye modelirovaniye i optimizatsiya upravleniya organizatsiyami [Economical and Mathematical Modeling and Optimization of Organizations' Management]. Dnepropetrovsk: Dnepropetrovsk University (in Russian), $540 \mathrm{p}$.

4. Kovalev V.V. (2007). Finansovyu menedzhment. Teoriya i praktika [Financial Management. Theory and Practice], $2^{\text {nd }}$ ed. Moscow: TK Velbi, Prospekt (in Russian), 1024 p.

5. Helfert E.A. (2003). Tekhnika finansovogo analiza [Techniques of Financial Analysis], $10^{\text {th }}$ ed. Saint-Petersburg: Piter (in Russian), $640 \mathrm{p}$

6. Berezhnaya Ye.V., Berezhnoy V.I. (2006). Matematicheskiye metody modelirovaniya ekonomicheskikh sistem [Mathematical Methods of Economical Systems' Modeling], 2nd ed., expanded and updated. Moscow: Finansy i Statistika (in Russian), 432 p.

7. Antonova L.V., Liakhovets O.O. (2011). Ekonometrika [Econometrics]. Mykolaiv: Chornomorskyi State University (in Ukrainian), $232 \mathrm{p}$.

8. Venttsel Ye.S. (1999). Teoriya veroyatnostey [Theory of Probability], $6^{\text {th }}$ ed. Moscow: Vysshaya shkola (in Russian), 576 p.

9. Lopatnikov L.I. (2003). Ekonomiko-matematicheskiy slovar: Slovar sovremennoy ekonomicheskoy nauki [Mathecon Dictionary: A Reference of Modern Applied and Mathematical Economics], $5^{\text {th }}$ ed., expanded and updated. Moscow: Delo (in Russian), 520 p.

\section{СРАВНЕНИЕ МЕТОДОВ КРАТКОСРОЧНОГО ПРОГНОЗИРОВАНИЯ ДЛЯ УБЫВАЮЩЕГО ПРОИЗВОДСТВЕННОГО ПРОЦЕСА}

Аннотация. Работа посвящена исследованию и сравнению методов краткосрочного планирования и прогнозирования. Основою оценивания являются данные предприятий, которые характеризуются убывающим процессом производства, т. е. функция дохода предприятия имеет во времени убывающий характер. Функция затрат, которая является базовой для данного исследования, также убывает, как и функция дохода. Оптимизация управления предприятиями в целом и планирование отдельных операционных периодов, как правило, опираются на экономико-математическое моделирование и прогнозирование изменения показателей производственных процессов. Прогноз всегда является многовариантным и предлагает несколько альтернативных решений, поэтому на основе приведенных в работе данных 
построены мультипликативная эконометрическая модель динамики часовых рядов и пропорциональная прогнозная модель на один период вперед. Оценены и сравнены ошибки прогнозов моделей. Важное условие исследования - небольшое количество данных наблюдений временного ряда (меньше 12), что в каждом случае отображается на результатах исследования.

Ключевые слова: эконометрическая модель, мультипликативная модель, авторегрессионное уравнение, автокорреляцияонная функция, пространственно-временные ряды.

\section{JUXTAPOSITION OF SHORT-TERM PROGNOSTICATION METHODS FOR DECREASING INDUSTRIAL PROCESSES}

Summary. The present work is dedicated to the investigation into the issue of short-term forecasting and prognostication methods, along with their juxtaposition. The methods applied include: dialectical method, observation method, critical and contrastive analysis and synthesis method. The research also has two more methods examined, first implying creation of econometric models of time series dynamics and second being proportional predictive method. The calculations are based on figures of a firm distinguished by its decreasing production process. This means that the firm's income function has decreasing character in time measurement. The expenditure function that is basic for the research conducted appears decreasing as well, but at a slower tempo than the income function. As a rule, optimization of firms' management at large and individual operational periods planning both rest on appliance of econometric modeling and prognostication of changes in industrial processes' figures. Forecast always turns multichoice and thus suggesting several alternative solutions. This is why the multiplicative econometric model of the time series dynamics as well as proportional predictive model for a single period in advance is being formed on the basis of the aforementioned figures. Hereupon, the errors of models' calculation are being computed and compared. The essential condition for conduct of this research proves to be the availability of a low number of time series observations data (up to 12), which obstructs the precision of calculations in each case under consideration. The research held has demonstrated that the error rate for a model formed via proportional method of prognostication recedes the one of regression autocorrelation model, with the mean relative error's value significantly shifting downwards as well. In the meanwhile, it is the regression autocorrelation model that better reflects the cumulative variation of expenditure function's time series levels for preceding periods. In this case a model's quality rating also turns of rather high predictive value. Both models imply calculations of expenditures predictive values that logically fit with the existing time series, whereas the proportional model lends higher tempo of the rate's increase. Furthermore, the research has proved that the proportional method holds a certain advantage, since here prognostication requires only two discrete quantities being expenditure values of two preceding periods. At the same time, the multiplicative model requires a sequential series of points marking the expenditure values for periods at an advisable number of over 12 .

Key words: econometric model, multiplicative model, autoregression equation, autocorrelation function, space-time series. 